\title{
THE ECONOMICS OF CLIMATE CHANGE IN AGRICULTURE
}

\author{
DAVID ZILBERMAN, XUEMEI LIU, DAVID ROLAND-HOLST and DAVID \\ SUNDING \\ Department of Agricultural and Resource Economics, University of California, Berkeley
}

(Received 6 March 2003; accepted in final form 16 October 2003)

\begin{abstract}
This paper presents a conceptual framework of the impact of climate change on agriculture. It assumes that climate change will result in a fertilization effect and a shift of agro-ecological conditions away from the Equator towards the Poles. The agro-ecological shift is likely to reduce yield because of reduced acreage and the fertilization effect will increase yield. The aggregate effect depends on whichever of the two dominates. The overall effect of climate change may be less significant than its distributional effects and the results are consistent with previous empirical studies. The impact of climate change depends on its pace. Faster changes in climate will result in higher cost. The assessment of the cost has to consider that climate change is a dynamic phenomenon that may require continuous adjustment. Environmental regulation that emphasizes conservation may increase cost of adjustment and environmental policies should emphasize adaptation and flexibility.
\end{abstract}

\section{Introduction}

There is growing evidence that concentrations of carbon dioxide $\left(\mathrm{CO}_{2}\right)$ in the atmosphere are on the rise and that it is largely due to human activities. Higher atmospheric $\mathrm{CO}_{2}$ levels have contributed to a global rise in temperature and changes in climatic conditions. Prospects are that this will continue. This raises a number of questions with respect to agriculture. How will climate change affect the economics of agriculture? How important is the phenomenon relative to other forces that shape the dynamics and economics of food and fiber? How can agricultural policies affect the dynamics of climate change and what are their likely impacts?

This paper draws upon a growing body of research conducted by economists in an attempt to answer these questions (see the reviews in Gitay et al. 2001; Lewandrowski and Schimmelpfennig 1999; Adams, Hurd and Reilly 1999; and Reilly 1999, 2002). In particular, they present a conceptual framework that can facilitate a formal analysis of the likely impact of climate change in agriculture and synthesis of prior empirical and anecdotal evidence. This framework reveals the importance of distributional and regional effects, which appear likely to outweigh overall effects. Then we argue that its impact depends on other dynamic processes, in particular, global population growth and productivity growth. 


\section{The Impact of Climate Change on Agriculture: A Conceptual Perspective}

While empirical evidence quantifying the impacts of climate change on agriculture has been increasing steadily, a conceptual framework to analyze this formally as not emerged. ${ }^{1}$ In particular, most of these studies investigate the impact of climate change on agriculture under status quo conditions of agricultural practices and ecological relationships and lack the general structure that would support counterfactual analysis. In this section, we extend a simple framework (set forth originally in Liu, Zilberman and Sunding, 2002) that can facilitate interpretation of findings in this literature and assess the impacts of varying initial and future conditions.

\subsection{THE MODELING FRAMEWORK}

Consider the pattern of agricultural production in a region (e.g., a continent, country, or district) that geographically spans significant latitude and a model that allows the crop mix to shift towards the Poles (as found in numerous studies). Locations have several dimensions that affect their climate, in particular, latitude and altitude. In the present model, the variable indicating location $(L)$ varies from 0 (closest location to the Equator) to 1 (the farthest away from the Equator). For simplicity, consider two crops (each may represent a composite crop mix or rotation) with $i$ as a crop indicator. One crop is termed heat-tolerant $(i=h)$ and is grown in areas closer to the Equator and the other is a cold-tolerant crop $(i=c)$ grown in areas closer to the Poles. The yield per acre of each crop at time $t$ is $y_{t}^{i}$, where $i \in(c, h)$. For simplicity, we have two periods: $t=0$, denoting initial (present) conditions and $t=1$, which denotes the period after which climate change occurs. ${ }^{2}$

Yields can then be seen to be a function of combined economic and environmental variables, i.e.,

$$
y_{t}^{i}=f_{t}^{i}\left(L, \operatorname{Clm}_{t}(L), \operatorname{Carb}_{t}, \operatorname{Tech}_{t}(L) P_{t}^{i}, W_{t}\right)
$$

where $^{3}$

$$
C L m_{t}(L)=\text { climate of location } L \text { at time } t
$$

$\operatorname{Carb}_{t}=$ atmospheric carbon concentration at time $t$

$$
\operatorname{Tech}_{t}^{i}(L)=\text { technology available at time } t
$$
and

$P_{t}^{i}=$ price of crop $i$ at time $t$

$W_{t}=$ price of agricultural inputs at time $t$.

1 See, for example, Mendelsohn, Nordhaus and Shaw 1994; Gitay et al. 2001.

2 For the time being, we assume farmers adjust instantaneously at $t=1$.

3 We do not aim at the moment to apply the model numerically, so we do not specify units of measurement here but emphasize conceptual analysis. 


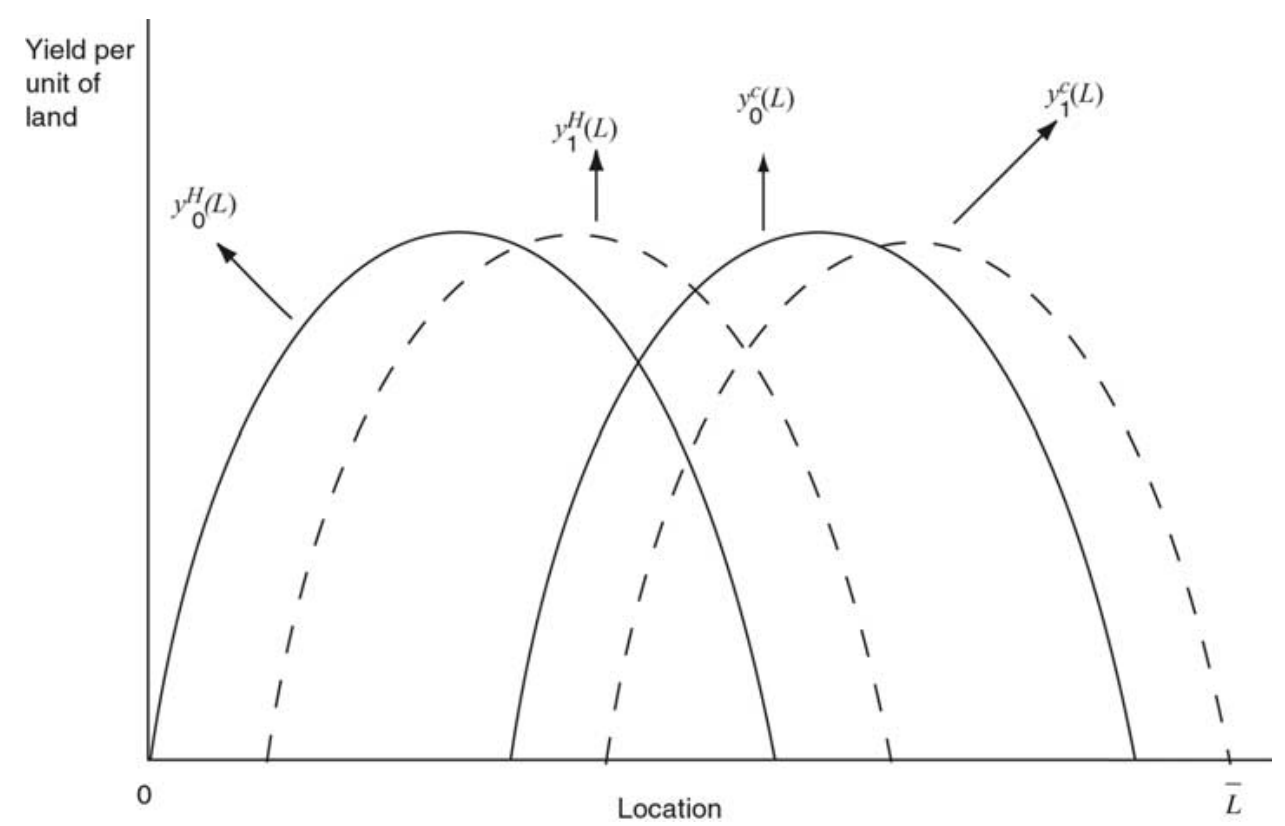

Figure 1. Impact of climatic change on yields (ignoring pest and fertilization effects).

The yield per unit of land function in (1) reflects choices of farmers to economic conditions given climatic and technological parameters. ${ }^{4}$

While climate has many dimensions, including temperature, precipitation, etc., it will be assumed for present discussion to be represented only by average temperature. Furthermore, we assume that there is a monotonic relationship between location (proxied by latitude) and climate. Climate (temperature) declines as the location (latitude) increases (i.e., one moves closer towards the Poles). Each crop is assumed to have a range of climate conditions (here an average temperature interval) where it survives. The yield of each crop reaches a maximum within its climate range and decreases with departures from this until it reaches zero. Holding other variables constant, we assume that the (marginal) distribution of yields within the location appropriate for each crop is unimodal and that the cold crop thrives in areas closer to the Poles than the warmer crop (see Figure 1). ${ }^{5}$

4 Following the neoclassical tradition, this function is derived from a production function, $\tilde{y}_{t}^{i}=\tilde{t}_{t}^{i}\left(L, \operatorname{Clm}_{t}(L), \operatorname{Carb}_{t}, \operatorname{Tech}_{t}(L), X_{T}^{i}(L)\right)$

where $X_{t}^{i}(L)$ is input use per unit of land in location $L$ at time $t$. Assuming profit maximization, the individual farmer chooses $X_{t}^{i}(L)$ solving

$\max _{X_{t}^{i}(L)} P_{t}^{i} \tilde{f}_{t}^{i}(., ., ., ., .)-,W_{t} X_{t}^{i}(L)$.

By solving for $S_{t}^{i}$ and plugging it into $\tilde{y}_{t}^{i}$, one obtains $y_{t}^{i}$.

5 Figure 1 reflects additional assumptions that are made only for graphic simplification. In particular, we assume that yield curves are strictly concave and yields reach zero at the point closest to the Equator. Neither assumption affects the results discussed here. 
The 'ecosystem movement' paradigm presented by Gitay et al. (2001) provides a first approximation of the impact of climate change on yield and we apply it here. We depict climate change as equivalent to a latitudinal shift of $\alpha$ miles towards the Equator. Thus, the climate after climate change at location $L$ is equal to the current climate at $L-\alpha$,

$$
C \operatorname{Cm}_{1}^{i}(L)=\operatorname{Clm}_{0}^{i}(L-\alpha),
$$

for $L \geq \alpha$. Thus, the direct impact of climate change on output is presented in Figure 1. The range of location where each crop is grown shifts away from the Equator by $\alpha$ miles and the yield of every crop at location $L$ after climate change is equal to the yield at location $L-\alpha$ before the change. Climate change can, of course, affect yields through channels other than temperature change, such as atmospheric chemistry, precipitation, solar radiation, etc.

In the present discussion, we assume the primary agent of climate change is increased atmospheric $\mathrm{CO}_{2}$ and this chemical transition affects yield through the 'fertilization' effect. Moreover, since $\mathrm{CO}_{2}$ is increasing for all crops and locations, it is plausible that, $\partial f_{t}^{i} / \partial C a r b>0$, i.e., climate change can increase yield through the fertilization effect. The impact of climate change is generalized to be

$$
y_{1}^{i}(L)=y_{0}^{i}(L-\alpha)\left[1+b_{i}(L)\right] .
$$

To maintain consistency with equation (1), the change in yield represented by $b_{i}(L)$ is also a function of changes in atmospheric carbon and the extent to which technology and prices respond to climate change. When the carbon effect dominates the price and technology effect, $b_{i}(L)$ will be positive and movement of climate results in higher yield (see Figure 2, where $b_{i}(L)$ are depicted as roughly equal for both crops).

The impact of climate change on land use generally depends on the profitability of the two crops. Profit per unit of land for crop $i$ at location $L$ in period $t$ is

$$
\pi_{t}^{i}(L)=P_{t}^{i} y_{t}^{i}(L)-W_{t}^{i} X_{t}^{i}(L),
$$

when $X_{t}^{i}(L)$ is the profit-maximizing input use level for crop $i$. Assuming there are no adjustment costs, the heat-tolerant crop will be selected at locations where $\pi_{t}^{H}(L)>\pi_{t}^{C}(L)$ and $\pi_{t}^{H}(L)>0$. The locations where the cold-tolerant crop is optimal are determined similarly. Locations that yield negative profits are not farmed.

When both crops are grown, it is useful to define several critical locations that separate regions with different patterns of production. The first location is $L_{t}^{H}$, which is the closest location to the Equator where the heat-tolerant crop is grown. Note that $\pi_{t}^{H}\left(\underline{L_{t}^{H}}\right)=0$ and it is negative for $L<\underline{L_{t}^{H}}$. A second significant location is $L_{t}^{S}$, the 'switching location' when both crops are equally profitable $\left(\pi_{t}^{H}\left(L_{t}^{S}\right)=\right.$ $\left.\pi_{t}^{C}\left(L_{t}^{S}\right)\right)$. The third significant location is $\bar{L}_{t}^{C}$, which is the farthest location away from the Equator where the cold-tolerant crop is grown. At $\bar{L}_{t}^{C}, \pi_{t}^{C}\left(\bar{L}_{t}^{C}\right)=0$, and 


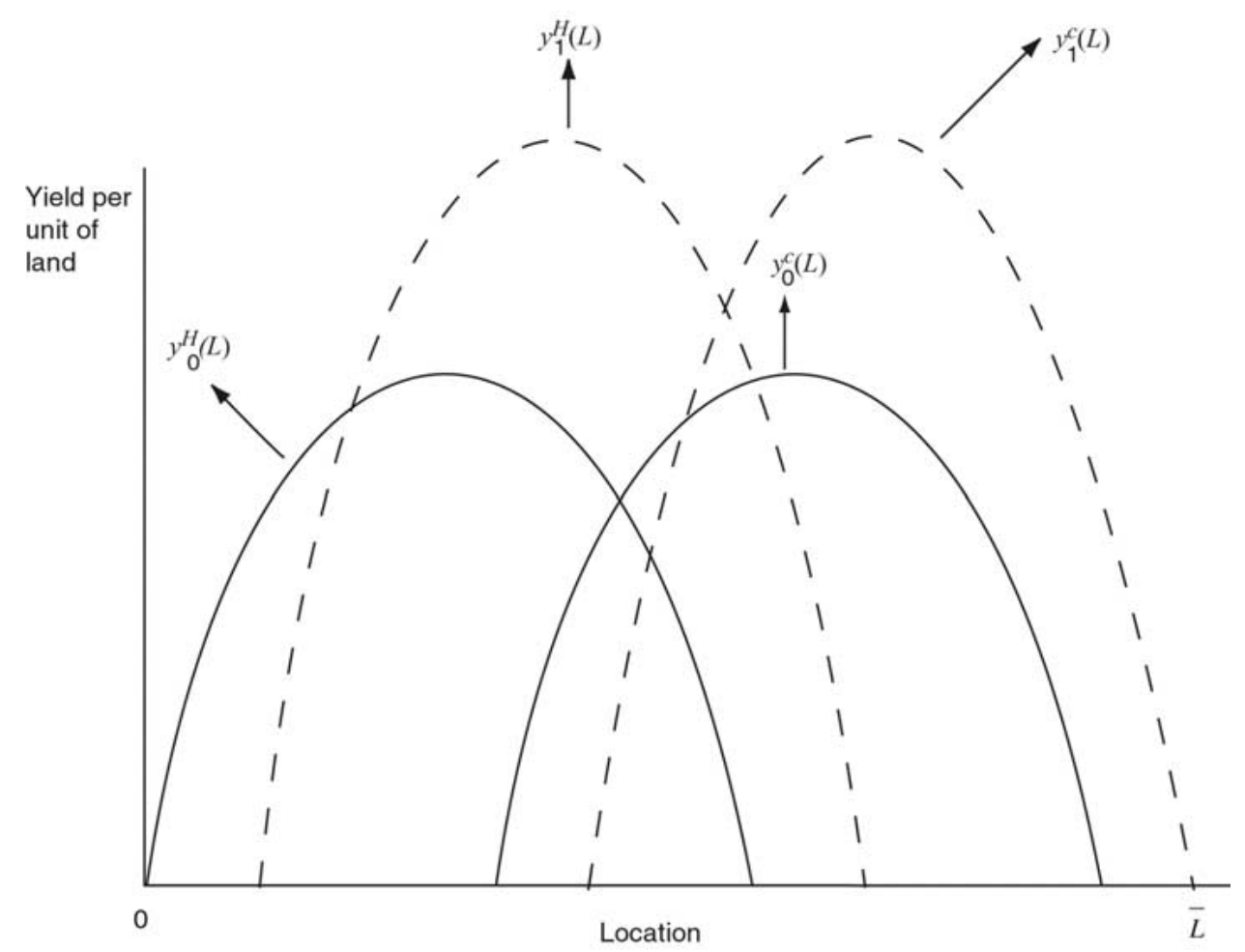

Figure 2. Impact of climatic change on yields (fertilization effect).

it is negative for $L>\bar{L}_{t}^{C}$. With this notation, during period $t$, the heat-tolerant crop is grown at $\underline{L}_{t}^{H} \leq L \leq L_{t}^{S}$, and the cold-tolerant crop is grown at $L_{t}^{S} \leq L \leq \bar{L}_{t}^{C}$. ${ }^{6}$

Consider first the hypothetical case when prices are invariant with respect to climate change, and $y_{1}^{i}(L)=y_{0}^{i}(L-\alpha)$. For this case, the same transformation that affects yield affects input use and profitability, so $X_{1}^{i}(L)=X_{0}^{i}(L-\alpha)$ and $\pi_{1}^{i}(L)=\pi_{0}^{i}(L-\alpha)$.

Liu, Zilberman and Sunding (2002) argue that, as with yields, the effect of climate change on profits can be approximated by a linear function,

$$
\pi_{1}^{i}(L)=\pi_{0}^{i}(L-\alpha)\left[1+b_{i}(L)\right]+c_{i}(L)
$$

where $c_{i}(L)$ and $b_{i}(L)$ are additive and multiplicative coefficients, respectively, that contribute (beyond $\pi_{0}^{i}(L-\alpha)$ ) to the profit at $L$ after climate change. In the more general cases when $P_{1}^{i}=P_{0}^{i}$, these coefficients reflect the impacts of changes in output price, including change in input use, in addition to the effect of fertilization and technology adjustments.

6 Obviously, we are assuming there are no returns to diversification. 


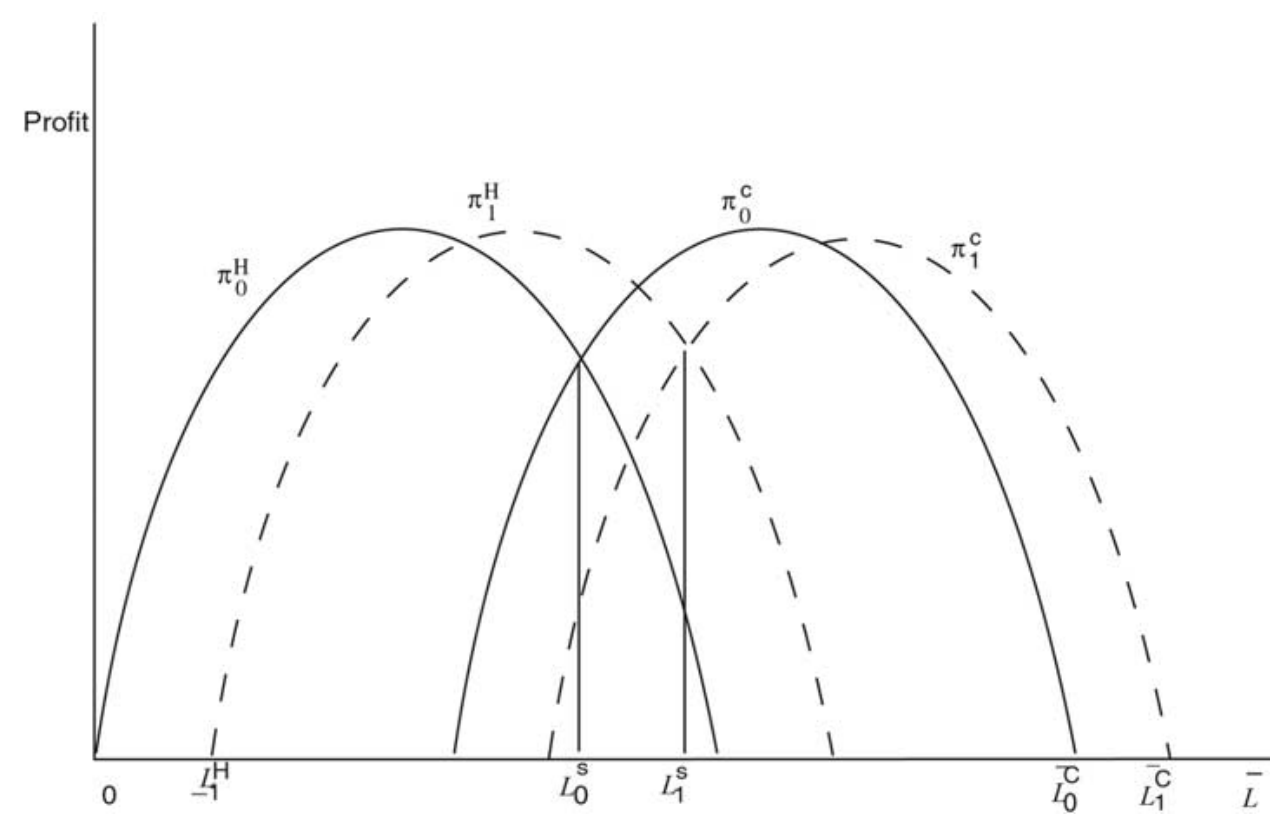

Figure 3. Climate change on profit (fixed prices and ecological shift).

For the hypothetical case when $y_{1}^{i}=y_{0}^{i}(L-\alpha)$ and assuming that prices do not change, $\pi_{1}^{i}=\pi_{0}^{i}(L-\alpha)$ and $b_{i}(L)=c_{i}(L)=0$, and this pattern is depicted in Figure 3.

Generally speaking, the transition of land-use patterns resulting from climate change will be qualitatively similar to those depicted above. In particular, there are five distinct regions between the Equator and the Poles. Closest to the Equator is a region that will become fallow after climate change. The next region will stay with heat-tolerant crops, followed by a region that will transit from cold-tolerant to heat-tolerant crops, a region that will stay with the cold-tolerant crops and a region that was not farmed before climate change but will be cultivated with coldtolerant crops. The exact location of the region depends on a combination of natural conditions (e.g., fertilization effects) and market adjustments that may be different for different crops (National Assessment Synthesis Team 2001). For example, the higher the fertilization gain for the cold-tolerant crop (at constant prices), the larger will be the expansion of production towards the Poles.

The hot crop was grown between $\underline{L}_{0}^{H}$ and $L_{0}^{S}$ before climate change and the cold one was grown between $L_{0}^{S}$ and $\bar{L}_{0}^{t}$. After climate change:

1. The land between $\underline{L}_{0}^{H}$ and $\underline{L}_{1}^{H}$ will be fallow. ${ }^{7}$

2. The land between $\bar{L}_{0}^{C}$ and $\bar{L}_{1}^{C}$ will be cultivated.

3. The land between $L_{0}^{S}$ and $L_{1}^{S}$ will switch from the cold crop to the hot crop.

$7 L_{0}^{H}$ is set to 0 in Figure 3. 
Now consider the case where $b_{i}(L)$ is positive. This corresponds to the assumption that climate change is associated with increased yields resulting from a 'fertilization effect.' If prices do not change, from (9), we have $\pi_{1}^{i}(L)>\pi_{0}^{i}(L-\alpha)$. Namely, the post-climate change profit at $L$ is greater than the pre-climate change profit at $L-\alpha$. Thus, profit at each location may increase or decline after climate change, with gains near the Poles and losses near the Equator.

In general, the overall effect of climate change on output and profitability of agriculture depends on land distributions across locations. Denoting acreage at location $L$ by $a(L)$, output of hot and cold crops at period $t$ is given by

$$
\begin{gathered}
Y_{t}^{H}=\int_{\underline{L}_{t}^{H}}^{L_{t}^{S}} y_{t}^{H}(L) a(L) d L, \\
Y_{t}^{C}=\int_{L_{t}^{S}}^{\bar{L}_{t}^{C}} y_{t}^{C}(L) a(L) d L,
\end{gathered}
$$

and farm sector profits at period $t$ follow as

$$
\Pi_{t}=\int_{\underline{L_{t}^{H}}}^{L_{t}^{S}} \Pi_{t}^{H}(L) a(L) d L+\int_{L_{t}^{S}}^{\bar{L}_{t}^{C}} \Pi_{t}^{C}(L) a(L) d L .
$$

Consider now the hypothetical case where

1. Climate change effects are equivalent only to direct movement, i.e., $y_{1}^{i}(L)=$ $y_{0}^{i}(L-\alpha)$.

2. Prices do not change as a result of climate change.

3. Acreage does not vary across locations, i.e., $a(L)=\bar{a}$.

Under these conditions, Liu, Zilberman and Sunding (2002) show that

1. Climate change will not change the output of either crop.

2. Climate change will not affect the profit of the industry.

This simplified reference case is useful for two reasons. First, the necessary assumptions for invariance of output and profits identify those factors that need closer analysis to explain real aggregate adjustments. Second, even though these conditions ensure climate change has no aggregate impact, it can have very substantial distributional affects. In particular, losers will be located close to the Equator and winners farther away. In the presence of homogeneous 'ecosystem movement' and a fertilization effect, production of the two crops and farmers' profits could actually increase with climate change under a regime of constant prices and uniform land distribution. However, there is less surface area (land or water) available for any 
activity as one moves toward the Poles, ${ }^{8}$ making both increase and decrease in aggregate production plausible.

The qualitative impact of climate change on aggregate production of the two crops is not clear when the fertilization and 'land availability' effects are combined. According to the National Assessment Synthesis Team (2001), yields of most crops are likely to increase substantially because of climate change, but acreage reductions associated with shifting of production toward the Poles will reduce production. Climate change will increase production if the fertilization effect dominates and decrease if the land availability effect dominates. Combining both effects across both crops compounds this ambiguity, but assessments of the overall effect of climate change on major crop categories are important empirical questions.

Studies reviewed by Gitay et al. (2001) and Reilley et al. (1996) document results that show both increases and decreases in aggregate supply, but these studies support the conclusion of Adams, Hurd and Reilley (1999), Lewandrowski and Schimmelpfennig (1999), and Mendelsohn, Nordhaus and Shaw (1994), who found that climate change does not pose a serious threat to the U. S. and global food capacity. The recent study of Reilly et al. (1996) suggests that a strong fertilizer effect is actually more likely to improve the aggregate food situation. On the other hand, the empirical simulations mentioned above suggest that the distributional effects of climate change are likely to be substantial. Adams, Hurd, and Reilly (1999) found that northern regions in the United States are likely to gain from climate change while southern regions are likely to lose. Rosenzweig and Iglesias (1994) argue that developing countries, which are concentrated in low latitudes, are more likely to lose from climate change, while the developed world is likely to gain. It is also reasonable to assume that these differences in incidence will be compounded by differential access to technology and investment resources.

\subsection{Food Demand And Climate CHANGE}

The assumption of fixed prices is unsatisfactory since food prices respond to changes in quality. Furthermore, demand for food may change over time and climate change may have a different impact under conditions of increased demand and growing food scarcity than under current conditions when agriculture in many countries suffers from excess supply problems. A more realistic approach to assessing climate change would take fuller account of both supply and demand. Indeed, the literature has long recognized the importance of price endogeniety. ${ }^{9}$

To this end, we extend the present framework for price endogeniety by using equations (5) and (6) to define supply functions $Y_{t}^{C}$ and $Y_{t}^{h}$ that are dependent on

8 There are approximately 6.5 billion hectares of land between the Equator and $30^{\circ}$ North and South, approximately 5.1 billion hectares between $30^{\circ}$ and $60^{\circ}$, and approximately 3.1 billion acres (including Antarctica) between $60^{\circ}$ and the Poles.

9 See, for example, Reilly and Hohmann (1993), Rosenzweig and Iglesias (1994) and many other studies since then. 
prices. In particular, we define $P_{t}^{C}$ and $P_{t}^{h}$ as prices of the two goods at different periods and denote corresponding demand functions by $D_{t}^{h}\left(P_{t}^{h}, P_{t}^{C}, \ldots\right)$ and $D_{t}^{C}\left(P_{t}^{h}, P_{t}^{C}, \ldots\right)$. Equilibrating supply and demand will establish the prices of the heat-tolerant and cold-tolerant crops. The properties of both demand and supply curves will determine the impact of climate change.

Thus, if the fertilization effect dominates the land availability effect for both crops, then supply of the two crops increases as a result of climate change. Liu, Zilberman and Sunding (2002) found that, under reasonable conditions, this will result in increase in output and reduction in prices of both crops, leading to consumer gains and producer losses. If climate change instead leads to higher cost of production and reduced supply, higher prices will negatively affect consumers while making producers better off.

Another possible scenario is that the supply of one crop, say, the heat-tolerant one, will increase, while the supply of the cold-tolerant crop may decline. That will reduce the price of the heat-tolerant crop and increase the price of the cold-tolerant crop. This may be quite devastating to the heat-tolerant crop producers near the Equator. Their yields will decline due to climate change and, at the same time, their prices will decline due to the increase in overall supply of the heat-tolerant crop. At the other end, growers of the cold-tolerant crop may benefit because of the higher price and growers of the heat-tolerant crop who are closer to the Poles may gain because of the higher yield.

Under this scenario, climate change will have significant distributional effects, as growers in the developed world, who are closer to the Poles, become better off and growers in the developing world, who are closer to the Equator, fare worse. These results are consistent with Rosenzweig and Iglesias (1994), but in a NorthSouth context the transboundary aspect of crop movement will complicate patterns of incidence. For these reasons, it is important to extend the present analytical framework globally and to take explicit account of boundary issues (nations or blocks of nations). The outcomes of climate change clearly depend on initial conditions of land distribution across locations. If a country has a rectangular shape and the land conditions are more or less equally homogeneous across locations, then a country near the Equator may lose as some land goes fallow and not be compensated by increased productivity due to the fertilization effect. However, symmetric reasoning demonstrates that rectangular countries closer to a Pole are more likely to experience increases in total arable land and net gains (including fertilization effects).

Across large countries, there are likely to be both regional winners and losers. Within multi-country regions and, more importantly, regional trading arrangements like the NAFTA, trade-offs may arise between competing domestic constituencies. For example, wheat producers in Canada may gain from climate change, while wheat growers in Texas and Oklahoma suffer. ${ }^{10}$ As it became apparent when dis-

10 See, for example, Adams et al. (1992) for a more detailed treatment of this case. 
cussing these issues in a North-South perspective, understanding climate change's global incidence, on agriculture and other economic activities, requires an examination of trade. For example, international price adjustments may offset or amplify the distributional effects, depending upon multinational demand and supply elasticities. $^{11}$

\subsection{OTHER CONSIDERATIONS}

The general economic discussion thus far has simplified the climate change process for the sake of analytical transparency, but many of the omitted components will exert important influences on the outcomes and must eventually be incorporated into the analysis. These include not only aggregate demand conditions, but also demand composition in sufficient regional and commodity detail to identify political economic issues (food security, etc.).

Geography matters greatly to this analysis. The longitudinal distribution of land significantly affects the impact of climate change. For example, Polar convergence (recession of available land as one moves toward to Poles) will attenuate the gains of the North, while the same effect amplifies the fallowing losses of the South. If land acreage declines as one moves away from the Equator, climate change will reduce output of both crops as well as overall farm profit. If, instead, acreage in a given region instead increases as agriculture shifts closer toward the Poles, output may increase and farmers' overall profits rise. Countries that are 'rectangular' in terms of their agricultural land are less likely to be affected than countries that are 'triangular' with respect to longitude. The importance of geography is already evidenced by the work of Butt et al. (2003), among others. In simulating the impact of climate change on Mali, they predict reduced production, significant loss to consumers and heightened food insecurity generally, but gains for agricultural producers due to higher prices.

Also important is the role of the public sector, particularly established programs in agriculture and food policy. For example, food prices are frequently depressed as agriculture tends to 'oversupply, and there is political economic pressure to support farm income and deal with food surplus issues (Gardner, 1992). As many researchers have already found, changes that will reduce supply may actually make some farmers better off and reduce the political pressure to support agriculture. Furthermore, some regions (Canada and northern United States) may actually flourish as they increase production and obtain higher prices.

In addition to modeling the basic properties of agricultural transition, a more complete analysis takes account of the opportunity cost of existing farm and fallow land. Land that may be used for agriculture may have alternative uses (e.g., wildland, urbanization), implying extensive indirect cost of lost environmental services

11 Thus, developing countries have long experienced term-of-trade volatility in primary commodities, including agricultural goods. 
and transaction cost associated with addressing legal issues of zoning and land-use regulations.

When considering the human dimension of climate change, it should be borne in mind that, while climate change is a global phenomenon, its impact may be felt most acutely in localities. Some regions may be impoverished and their rural populations will need new sources of income and support, while others will enjoy a bonanza. For these reasons, climate change may lead to enhanced patterns of migration.

Finally, we have used a general concept of 'fertilization' to proxy the net effects of climate change on biological productivity in crops. These are understood to include both positive effects, like ambient carbon enhancement and negative ones, like pest damage. Implicitly, we are assuming that pest and host responses to climate change are identical. In reality, there is both theoretical and empirical work to do on this question for individual climatic and crop cases (Gitay et al. 2001). This will be further discussed in the next section, but nevertheless, a more complete treatment requires that pest response be decomposed to identify its individual effects and mitigation strategies.

\section{Adjustment to Climate Change}

The analysis thus far assumed that induced ecological transition or movement is a smooth, costless process and that relatively simple price adjustments and fertilization effects determine post-climate change yields. Among other expert assessments, however, the Gitay et al.'s IPCC report (2001, p. 248) and other authors (e.g., Quiggin and Horowitz 2003) suggest that paradigm of 'ecological movement' is unlikely to be very robust, i.e., climate change could induce significant pest damages that are difficult and costly to address. Differences in soil conditions and solar radiation across latitudes may also change yield patterns during and after adjustment to climate change.

Another prominent secondary effect of climate change concerns water supply and demand. The former includes changes in precipitation snowmelt, water retention, and distribution capacity. These effects are unlikely to be distributed with any uniformity and certainly need not be conformed to existing patterns of natural and manmade water distribution capacity. Riverine systems in higher latitudes will experience greater risk to flooding, while lower latitudes will see water systems recede. Foothill regions may need to build or expand their dams. Other regions may lose their water and, thus, be required to identify new sources of delivery. ${ }^{12}$ Irrigation systems may undergo extensive chemical evolution-with rising deposition/salinization in some areas and soil leaching/depletion in others. Some regions

12 The seasonal dimensions of water supply and demand are very important and both can be expected to change with global warming. Howitt and Lund (2002) and other authors have examined this issue. 
blessed today with drier climates (California) and relatively low pest loads may become hotter and more humid, inducing an upsurge among pest species.

Changing weather patterns, ecological conditions and pest problems will require significant modifications in crop systems at critical locations. As Olmstead and Rhode (1993) have shown, the evolution of crop systems in the United States has been a slow and deliberate process. Thus, a comprehensive policy response to climate change should develop a capacity to respond more quickly to changing conditions. The challenge here is substantial since it entails not only development of knowledge, but also significant commitments to education and technology transfer to promote the right patterns of adaptation/adoption. Differences among countries and regions in terms of their ability to adapt could be a significant determinant of the costs and benefits they experience from climate change. Clearly, developing countries will be at a disadvantage in this context and these facts, combined with unfavorable initial conditions (low latitude, etc.), will conspire to make them the main victims of climate change. Since adaptation takes time, the magnitude of the impact will depend on the speed of the process and the timeliness of responses. If climate changes are brisk, even countries like the United States may have difficulty adjusting, given the implied relocation and adaptation of crop patterns and production technologies. Thus, a more pragmatic orientation for research in this area is not whether climate change will occur, but when and how fast. More awareness of this issue would enable policymakers to move from an agenda of speculation and abstract risk assessment to one of readiness, sequencing and forward-looking pro-activity.

From a conceptual perspective, the adjustment associated with climate change requires investments to increase or maintain $b_{i}(L)$, the yield coefficient in (8). Some of these investments are public (in research and extension, roads, infrastructure) and some are private. Adjustments to climate change are likely to reduce the yield effect and profitability under climate change and may even be sufficient in reversing the higher output and lower price effects of strong fertilization effects.

Figure 4 expands the framework presented earlier to account for adjustment costs. We conduct the analysis without considering the fertilization effect and assume two forms of adjustment cost. First, transition costs (TC) from one technology to another, from the cold-tolerant crop to the heat-tolerant crop, are fixed in per acre terms. Second, settlement costs (ST) reflect the adjustment costs associated with settlement of new land close to the Poles. If transition costs (TC) are equal to $\mathrm{AB}$, then at the switching location after climate change, $\pi_{1}^{C}\left(L_{i}^{S}\right)-\pi_{1}^{H}\left(L_{i}^{S}\right)=T C$. Indeed, transition costs simply move the switching location to the left (point $E$ in Figure 4).

Similarly, with settlement cost $S C=C D$, the utmost limit of settlement $\bar{L}_{1}^{C}$ is at the point where $\bar{L}_{1}^{C}\left(L_{1}^{C}\right)=S C$. This point is to the left of $\bar{L}_{1}^{C}$ of Figure 2, where settlement cost was assumed to be zero. Thus, as intuition dictates, transition and settlement costs reduce the scope for adaptation and resettlement in response to climate change. These costs, therefore, result in reduction of supply relative to 


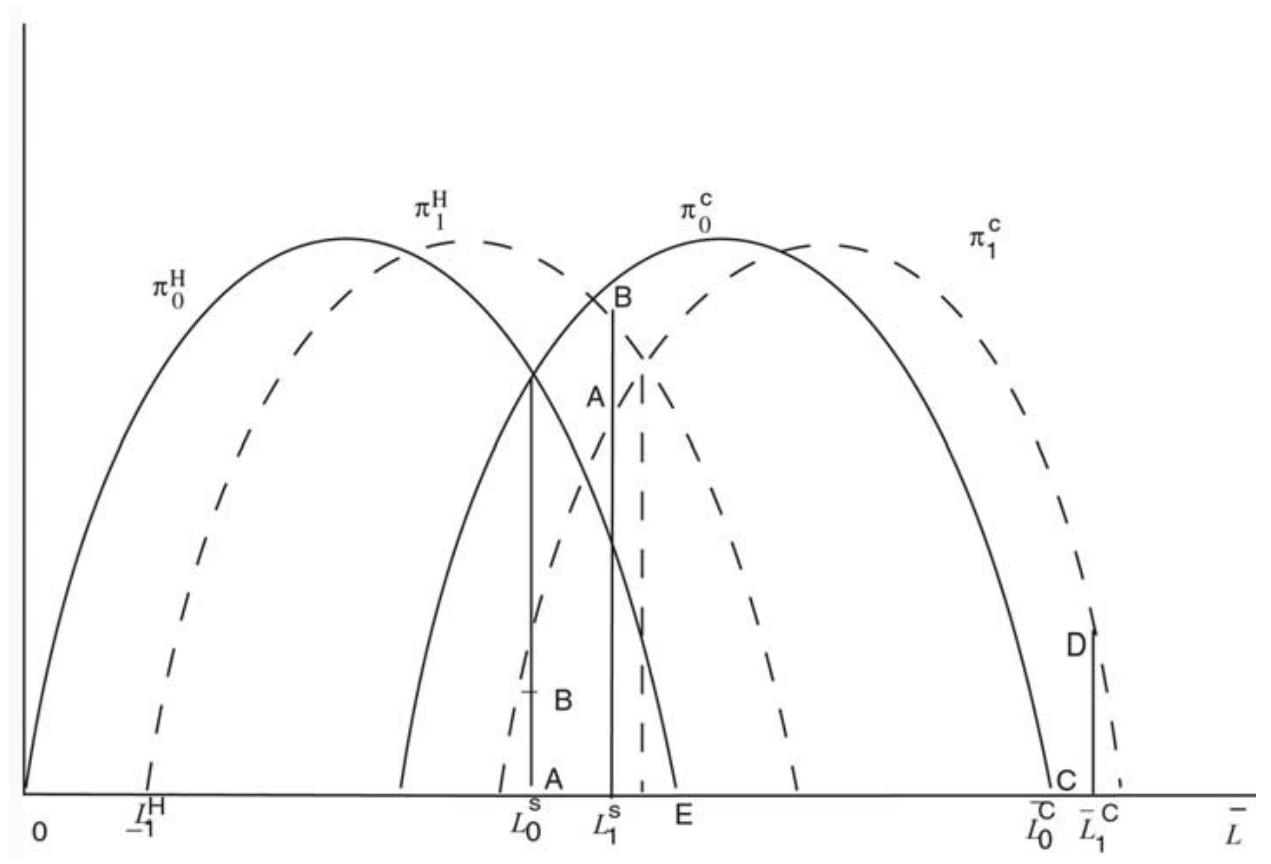

Figure 4. Impact of transition cost.

the case of no cost and thus transition of settlement costs increase the social cost of climate change. This translates into more negative impacts on consumers, who bear the ultimate cost of reduced supply.

The final outcome of climate change is dependent on interactions among the adjustment costs, fertilization effects, and land availability effects. As Quiggin and Horowitz (2003) argue, the adjustment cost may be very substantial and could represent a major element of climate change. Adjustment costs arising from climate change can in any case be expected to be quite pervasive, extending through complex chains of technological, agrarian, and demographic adaptation.

In addition to adjustment costs induced by climate change, costs associated with prospective actions like research and public policy should also be considered. The public sector can be expected to play a prominent role in the adjustment process and in determining its ultimate costs to the private sector. By promoting research on adaptation of crop systems and land use, public funds can reduce direct and indirect adjustment costs. From another angle, some regulations established to protect environmental quality may have the unintended consequence of slowing adjustment to climate change because wilderness areas and other land may be protected in ways that prevent their conversion to agriculture. The Endangered Species Act is essential for conservation, yet may pose some obstacles in an era of adjustment and transition. Thus, there will be a need for a delicate balance in environmental 
regulation, allowing adjustment and reducing transaction costs while protecting valuable environmental amenities.

\section{Climate Change and Other Forces Affecting Agriculture}

Some empirical studies on the impact of climate change (e.g. Mendelsohn and Dinar, 1999) use current land rent data as a proxy to assess the gains from farming. ${ }^{13}$ These empirical studies largely consist of regression results that relate rents to climatic conditions. For each location, predicted weather patterns after climate change are used to estimate the implied changes in land rent in response to climatic change. This approach is sound methodologically if rents represent profits under a truly competitive regime. However, we are currently in the midst of an agricultural crisis due to oversupply and artificially low producer prices. Most U.S. farmland receives the majority of its income from government support programs. Farmers' rent thus reflects not only the incremental economic contribution of land and associated resources (climate), but also the transfer received by farmers from the government. In many cases, this may lead to overestimation of benefits and, since government payments are not distributed evenly, this deviation of the rents from marginal economic values varies across locations. The use of rent data without correction for commodity programs leads to a distorted impact assessment.

Even if climate change reduces supply under current environmental policies, the impact will be smaller than what can be derived assuming competitive behavior (Lichtenberg and Zilberman 1986). Reduction in supply will lead to an increase in prices and reduced government spending on farm support. Thus, if the supply reduction effect of climate change is mild under the current situation, it would not have much of a negative impact. However, climate change may have other more dramatic effects, such as occasional floods and droughts. Furthermore, the impact of climate change on yield is complex and has to take into account a variety of factors, many of which vary with location. This makes general inferences and imputations more difficult.

The rent studies assess only part of the economic impact of climate change. They do not consider the infrastructure, settlement and other adjustment costs and the current empirical models also fail to account for fertilization and pesticides effects. Their main shortcoming, however, arises from the fact that climate change is likely to occur 50 years or so in the future. In modern history, current agricultural economic conditions have not been reliable indicators of future conditions over a time span like this. With the rapid evolution of government intervention in this sector and globalization of food marketing, it is unlikely that status quo assumptions about agricultural supply and demand patterns will yield anything approaching rational expectations over the coming decades.

13 Such rents correspond to profits per unit of land $\left(\pi_{i}\right)$ in our analysis. 
The story of agriculture in the last two centuries has been about a race between population growth and technological progress. Global population grew from 1 billion people in 1800, to 2.5 billion people in 1950, to 6 billion people in 2000 . Meanwhile, food per capita has increased in spite of this massive growth of human population. Much of the increase of the food supply in the $19^{\text {th }}$ century was achieved by an increase in farmed acreage. Since World War II, however, much of the increase in agricultural productivity is due to intensification, namely, use of modern inputs such as fertilizers and chemicals, high yield varieties and irrigation. For example, $40 \%$ of the world's food is produced on $15 \%$ of arable irrigated land and most of the irrigation was introduced in the last 50 years.

While population projections might be more reliable than those of atmospheric warming, global population trends are still uncertain. There is some probability that global population may exceed 15 billion by the end of the century. It may grow to 10-11 billion or may stabilize at a smaller number of people (United Nations, 2003). If global population does not grow much over time, then the impact of climate change in terms of agriculture may not be substantial. Of course, some regions may be affected more than others, but the aggregate effect will not be much. If the population rises by $5-10$ billion over the next $50-100$ years and average incomes also rise, demand for more resource intensive foods such as meat may increase substantially. Society will then need to double its agricultural output. Studies such as those of IFPRI suggest that technology and acreage increases will need to meet the extra demand and prices may actually decline; yet, the source of new supplies remains to be identified.

Even if the trend of increased productivity and declining prices continues over the long term, climate change may induce short-term adjustments that significantly disrupt this progress. For example, incremental adjustments to climate change (e.g., re-location) may be accompanied by short-term supply shortages, affecting welfare locally, regionally and perhaps beyond. Even in the last few decades, we have seen years where food balances were threatened and a large-scale disruption like climate change may increase the frequency of such moments of vulnerability. The path toward long-term growth may not be monotonic.

As researchers, we are part of a historical process that combines experience and expectations. Even 30 years ago, there were also discordant voices about the future of population and global resources and food in particular. Since then, average living standards, including nutritional status and many other welfare indicators, have risen dramatically and global food prices have fallen monotonically. We have gone through an era where we exploited many yield-increasing technologies, but we have never been guaranteed that new discoveries will generate alternative or better technologies. One way to increase supply is to combine increased yield with increased acreage, but that may lead to significant environmental effects. If the increase of supply becomes difficult under current conditions, it may become even more difficult in the presence of a changing climatic regime. Two features of climate change might render our past experience less meaningful: It is pervasive and 
may change fundamental properties of agricultural production and it is also unprecedented in modern experience, meaning our understanding of its implications is very incomplete. For these reasons, recent trends of technological overtaking may not be sustainable. If a substantial increase in population combines with rapidly changing environmental conditions, technological change may start lagging behind population growth.

The above discussion emphasizes that the overall effect of climate change on prices depends on the dynamics of population and technology. However, as argued earlier, the pace of climate change will affect its impact and the capacity to adjust. Second, the impacts will vary quite significantly across locations. Some regions will experience spontaneous benefits and others will face new challenges. Both migration and trade will affect these adjustments, especially in negatively affected areas. In some cases, regions may lose their capacity to support themselves, and large groups of people may find themselves trapped in increasingly adverse circumstances. Like the AIDS/HIV phenomenon, this process may induce more coordinated global policies committed to alleviate human suffering (Gitay et al. 2001, p. 491).

\section{Conclusion}

This paper argues that the economic impact of climate change on agriculture should be analyzed within a disaggregated modeling system that captures spatial characteristics and agricultural productivity changes. With respect to the former, we propose a new conceptual framework for modeling the yield effects of climateinduced crop movements. A succinct formal approach like this can yield some interesting general conclusions, but we also see it as the kernel of a larger commitment to empirical research that will be necessary to better understand linkages between climate change and agriculture and especially to identify the regional economic and social trade-offs that face policymakers.

Generally speaking, our theoretical analysis indicates that aggregate effects of climate change may be moderate, but inside the global envelope there will be dramatic compositional adjustments and significant winners and losers. This view already has many adherents, but its policy implications need wider acceptance. The complexity of the underlying processes means that policymakers relying on rules of thumb alone are unlikely to achieve anything approaching optimality. For that reason, we believe the research community has an important responsibility to improve visibility for them by advancing empirical work in this area.

Our approach to the agricultural productivity issue was to distill recent thinking about salient issues, including technological change, climate-induced changes in pest relationships and atmospheric carbon. Productivity growth has been and will remain the most important line of defense for global food and farm security. As long as the food supply grows faster than population and demand, we do not have 
to be concerned about climate change on an aggregate level. However, there is a serious (but still highly uncertain) risk that supply may fall further behind demand and that climate change may lead to significant food shortages and price increases. From a strategic perspective, this means research and policy resources must also go to improved monitoring and calibration of climate-agricultural trends. Combining traditional investment in agricultural productivity with improved technology for weather/climate analysis will facilitate better public and private responses to emerging adjustment challenges.

The unequal geographic distribution of climate change impacts points to a need for inter-regional policy frameworks that can facilitate mutual assistance and accommodation during periods of significant adjustment or crisis. While the overall world agricultural system may be able to withstand climatic changes, substantial existing farm and rural regions may be devastated by climate change and we anticipate the needs of these populations, including relocation, if we are to avert greater suffering.

Climate change is an environmental and economic policy challenge that requires effective deployment of many scientific and technological resources. Because agriculture (directly of indirectly) secures the livelihood of most of the world's population, the risks that climate changes pose to food and farm security should be paramount in the minds of national and global strategists.

\section{References}

Adams, R.M., Hurd, B.H. and Reilly, J.: 1999, Agriculture and Global Climate Change: A Review of Impacts to U.S. Agricultural Resources, Arlington, VA, Pew Center on Global Climate Change.

Butt, T.A., McCarl, B.A., Angerer, J., Dyke, P.T. and Stuth, J.W.: 2003, Food Security Implication of Climate Change in Developing Countries: Findings from a Case Study in Mali, Working Paper, Department of Agricultural Economics, Texas A\&M University, College Station, TX.

Gardner, B.: 1992, 'Changing economic perspectives on the farm problem,' J. Econ. Literature 30, 62-101.

Gitay, H., Brown, S., Easterling, W., Jallow, B., Antle, J., Apps, M., Beamish, R., Chapin, T., Cramer, W., Frangi, J., Laine, J., Erda, L., Magnuson, J., Noble, I., Price, J., Prowse, T., Root, T., Schulze, E., Sirotenko, O., Sohngen, B. and Soussana, J.: 2001, Ecosystems and Their Goods and Services, Chapter 5 in: Intergovernmental Panel on Climate Change (IPCC). Climate Change 2001: Impacts, Adaptation and Vulnerability; Contribution of Working Group II to the Third Assessment Report of the Intergovernmental Panel on Climate Change, Cambridge, United Kingdom, Cambridge University Press, pp. 235-342.

Howitt, R.E. and Lund, J.: 2002, 'Water will drive California response to climate change,' California Agric., May-June.

Lal, R., Kimble, J., Follett, R. and Cole, C.: 1998, The Potential of U.S. Cropland to Sequester Cabon and Mitigate the Greenhouse Effect, Chelsea, Michigan, Sleeping Bear Press.

Lewandrowski, J. and Schimmelpfennig, D.: 1999, 'Economic implications of climate change for U.S. agriculture: Assessing recent evidence,' Land Economics 75(1).

Lichtenberg, E. and Zilberman, D.: 1986, 'The welfare economics of price supports in U.S. agriculture,' Amer. Econ. Rev. 76(5), December, 1135-1141. 
Liu, X., Zilberman, D. and Sunding, D.: 2002, The Impact of Climate Change on Agriculture: A Conceptual Study, Berkeley, Department of Agricultural and Resource Economics, Working Paper, University of California.

Mendelsohn, R. and Dinar, A.: 1999, 'Climate change, agriculture and developing countries: Does adoption matter?', World Bank Observer 14(2), 277-293.

Mendelsohn, R., Nordhaus, W. and Shaw, D.: 1994, 'The impact of global warming on agriculture: A Ricardian analysis', Amer. Econ. Rev. 84(4), 753-771.

National Assessment Synthesis Team: 2001, Climate Change Impacts on the United States Foundation Report, New York, Cambridge University Press.

Olmstead, A.L. and Rhode, P.: 1993, 'Induced innovation in American agriculture: A reconsideration', J. Pol. Econ. 101(1), 100-118.

Quiggin, J. and Horowitz, J.: 2003, Costs of Adjustment to Climate Change, Working Paper, Department of Economics, University of Maryland.

Reilly, J., Bzethgen, W., Chege, F.E., van de Greijin, S.C., Ferda, L., Iglesias, A., Kenny, C., Patterson, D., Rogasik, J., Rotter, R., Rosenzweig, C., Sombroek, W. and Westbrook, J.: 1996, 'Agriculture in a changing climate: Impacts and adaptations', in Watson et al. (eds.), Climate Change, 1995: Impact, Adaptation and Mitigation of Climate Change - Scientific - Technical Analyses, New York, Cambridge University Press.

Reilly, J. and Hohmann, N.: 1993, 'Climate change and agriculture: The role of international trade,' Amer. Econ. Rev. 83, 306-312.

Reilly, J.: 1999, 'Climate change and agriculture: The state of the scientific knowledge,' Climatic Change 43(4), 645-650.

Reilly, J. (ed.): 2002, Agriculture: The Potential Consequences of Climate Variability and Change for the United States, New York, Cambridge University Press.

Rosenzweig, C. and Iglesias, A.: 1994, Implications of Climate Change for International Agriculture: Crop Modeling Study, Washington, D.C., U.S. Environmental Protection Agency, Climate Change Division.

United Nations: 2003, World Population Prospects: 2002 Revision, New York, United Nations. 